\title{
Sphingobium amiense sp. nov., a novel nonylphenol-degrading bacterium isolated from a river sediment
}

\author{
Yuuji Ushiba, Yoshiharu Takahara and Hiroyuki Ohta
}

Correspondence

Hiroyuki Ohta

hohta@mx.ibaraki.ac.jp

\author{
Department of Bioresource Science, Ibaraki University College of Agriculture, Ami-machi, \\ Ibaraki 300-0393, Japan
}

\begin{abstract}
A nonylphenol-degrading bacterial strain $\left(\mathrm{YT}^{\mathrm{T}}\right)$ was isolated previously from a river sediment sample obtained in Ami-machi, Ibaraki, Japan, and identified as a Sphingomonas species. In this study, the taxonomic relationship between strain $\mathrm{YT}^{\top}$, a recently described nonylphenol-degrading strain, Sphingomonas cloacae, and Sphingobium yanoikuyae, which is phylogenetically related, was examined. Their phenotypic characteristics were compared and levels of DNA-DNA relatedness between these strains were determined. Based on the results of physiological and biochemical tests and DNA-DNA hybridization, it is proposed that strain $\mathrm{YT}^{\top}$ (=IAM $15006^{\top}=\mathrm{JCM} 11777^{\top}=\mathrm{CIP} 107839^{\top}$ ) represents a novel species of the genus Sphingobium, Sphingobium amiense sp. nov.
\end{abstract}

Nonylphenol (NP) and the shorter homologues of nonionic surfactants, nonylphenol polyethoxylates $\left(\mathrm{NPEO}_{x}\right)$, are known to exert oestrogenic effects in aquatic organisms (Soto et al., 1991; White et al., 1994; Brown et al., 1999; Kloas et al., 1999; Kinnberg et al., 2000). In the aquatic environment, microbial breakdown of $\mathrm{NPEO}_{x}$ yields shorter homologues under aerobic conditions and further NP under anaerobic conditions (Rudling \& Solyom, 1974; Giger et al., 1984; Kveštak \& Ahel, 1995). Although NP is rather recalcitrant in the environment, especially in anoxic sediments (Ahel et al., 1996; Heinis et al., 1999), both Tanghe et al. (1999) and Fujii et al. (2000) have recently isolated Sphingomonas strains that were able to grow on a commercial mixture of branched NP isomers as a sole carbon and energy source in pure culture. Strain $\mathrm{S}-3^{\mathrm{T}}$, described by Fujii et al. (2000), degraded 1000 p.p.m. NP, i.e. a concentration 10000-1000000-fold higher than that found in urban environments, almost completely within 10 days. In their further taxonomic study, this strain was placed in a novel species of the genus Sphingomonas, Sphingomonas cloacae (Fujii et al., 2001).

Recently, a conventional enrichment culture was carried out on 10 p.p.m. NP, with diluted nutrient broth (NB) for additional organic nutrients, to isolate bacterial strains able to degrade NP at low levels. From this enrichment culture, an NP-degrading strain $\left(\mathrm{YT}^{\mathrm{T}}\right)$ was isolated and characterized chemotaxonomically and phylogenetically (de Vries et al., 2001).

Abbreviations: NP, nonylphenol; NPEO ${ }_{x}$, nonylphenol polyethoxylates. The DDBJ accession number for the $16 \mathrm{~S}$ rDNA sequence of strain $\mathrm{YT}^{\top}$ is AB047364.
Strain $\mathrm{YT}^{\mathrm{T}}$ is a Gram-negative, yellow-pigmented rod that contains ubiquinone with 10 isoprene units (Q-10) and alkali-stable sphingoglycolipid. In addition, 16S rDNA sequence analysis revealed that strain $\mathrm{YT}^{\mathrm{T}}$ belonged to Sphingobium (Sphingomonas cluster II), recently proposed by Takeuchi et al. (2001). The closest known relatives of strain $\mathrm{YT}^{\mathrm{T}}$ were Sphingobium yanoikuyae and the recently described NP-degrading Sphingomonas cloacae, with 16S rDNA similarity values of $98 \cdot 0$ and $97 \cdot 8 \%$, respectively (de Vries et al., 2001). Based on these results, strain $\mathrm{YT}^{\mathrm{T}}$ was classified as a member of the genus Sphingomonas (de Vries et al., 2001). In the present study, other phenotypic and chemotaxonomic characteristics of strain $\mathrm{YT}^{\mathrm{T}}$ and the DNA-DNA relatedness between $\mathrm{YT}^{\mathrm{T}}$ and closely related strains of Sphingobium yanoikuyae and Sphingomonas cloacae were examined.

Sphingobium chlorophenolicum JCM $10275^{\mathrm{T}}$, Sphingomonas cloacae JCM $10874^{\mathrm{T}}$, Sphingomonas paucimobilis JCM $7516^{\mathrm{T}}$ and Sphingobium yanoikuyae JCM $7371^{\mathrm{T}}$ were obtained from the Japan Collection of Microorganisms. Sphingobium chlorophenolicum DSM 8671, obtained from the DSMZ, was also used in some experiments. NB [1\% (w/v) Ehrlich meat extract (Kyokuto Seiyaku), $1 \%(w / v)$ Trypticase peptone (Becton Dickinson) and $0.5 \%(\mathrm{w} / \mathrm{v})$ $\mathrm{NaCl}]$ or its 10 -fold dilution $(\mathrm{NB} / 10)$ was used for cultivation. The $\mathrm{pH}$ was adjusted to $7 \cdot 0$ with $1 \mathrm{M} \mathrm{NaOH}$. Unless otherwise indicated, strains were grown aerobically at $27^{\circ} \mathrm{C}$ on NB/10 or NB agar medium.

For electron microscopy, cells of strain $\mathrm{YT}^{\mathrm{T}}$ were grown on $\mathrm{NB} / 10$ for 3 days, suspended in $50 \mu \mathrm{l} 20 \mathrm{mM}$ ammonium acetate and dried on a carbon-coated mesh. Cells were 
stained with $0 \cdot 1 \%(\mathrm{w} / \mathrm{v})$ phosphotungstic acid and observed under a Hitachi H-800 transmission electron microscope at $100 \mathrm{kV}$. Growth of strain $\mathrm{YT}^{\mathrm{T}}$ at 4, 30 and $42{ }^{\circ} \mathrm{C}$ on $\mathrm{NB}$ was monitored for 7 days. Nitrate reduction was tested by growing strain $\mathrm{YT}^{\mathrm{T}}$ in $\mathrm{NB}$ and $\mathrm{NB} / 10$ supplemented with $0 \cdot 1 \%(\mathrm{w} / \mathrm{v}) \mathrm{KNO}_{3}$ and then adding Griess-Ilosvay reagents (Skerman, 1967) to the culture. Assimilation of organic compounds, including carbohydrates and organic acids, activities of arginine dihydrolase, urease and $\beta$-galactosidase, hydrolysis of aesculin and gelatin and production of indole were tested using API 20NE (bioMérieux). The tests were run according to the manual and incubated at $27^{\circ} \mathrm{C}$ for 4 days. Oxidase and catalase tests were carried out as described previously (Ohta \& Hattori, 1983). Cellular fatty acids were analysed as described previously (Ohta \& Hattori, 1983). In brief, cellular fatty acid methyl esters were prepared by heating dried cells in anhydrous methanolic $\mathrm{HCl}$ at $100{ }^{\circ} \mathrm{C}$ for $3 \mathrm{~h}$ (Ikemoto et al., 1978) and then analysed by GLC. A column $(4 \cdot 1 \mathrm{~m} \times 2.6 \mathrm{~mm})$ with $10 \%$ dimethyleneglycol succinate on Chromosorb W (AW-DMCS, 80-100 mesh) was used. For the detection of hydroxy fatty acids, TLC (Kieselgel F-254; Merck) was used with a hexane/diethyl ether $(4: 1, \mathrm{v} / \mathrm{v})$ solvent system. To compare cellular protein profiles, whole-cell lysates with SDS were prepared essentially as described by Ohta et al. (1993) and onedimensional analytical SDS-PAGE was performed by the method of Laemmli (1970) with a $12.5 \%$ separating gel and a $4.5 \%$ stacking gel. Proteins were visualized by silver staining with a commercial kit (Daiichi Pure Chemicals).

In a previous work, the $16 \mathrm{~S}$ rDNA sequence of strain $\mathrm{YT}^{\mathrm{T}}$ was determined, indicating that the strain belongs to the genus Sphingomonas (de Vries et al., 2001). In the present study, sequences that exhibited close relatedness in a FASTA (Pearson \& Lipman, 1988) search and those of representative species in Sphingomonas sensu lato were used for phylogenetic analysis. Multiple alignment, calculation of nucleotide substitution rates ( $K_{\text {nuc }}$ values) as described by Kimura (1980) and construction of a phylogenetic tree by the neighbour-joining method (Saitou \& Nei, 1987) were performed using CLUSTAL W (Thompson et al., 1994). Sequence similarity calculations indicated that the closest relatives of strain $\mathrm{YT}^{\mathrm{T}}$ were Sphingobium yanoikuyae $(98 \cdot 0 \%)$, Sphingomonas cloacae $(97 \cdot 8 \%)$, Sphingobium chlorophenolicum $(97 \cdot 1 \%)$, 'Sphingomonas agrestis' (96.8\%) (Pinyakong et al., 2003), Sphingobium herbicidovorans $(96 \cdot 8 \%)$ and Sphingomonas chungbukensis $(96 \cdot 4 \%)$. For determination of DNA base composition, DNA was extracted, purified by phenol treatment (Saitou \& Miura, 1963) and enzymically degraded into nucleosides. The nucleoside mixture was separated by reverse-phase HPLC as described by Tamaoka \& Komagata (1984). DNA-DNA hybridization experiments were carried out with photobiotin-labelled probes in microplate wells as described by Ezaki et al. (1989) using a Wallac 1420 ARVOsx multilabel counter for determination of chemiluminescence. For enzymic development,

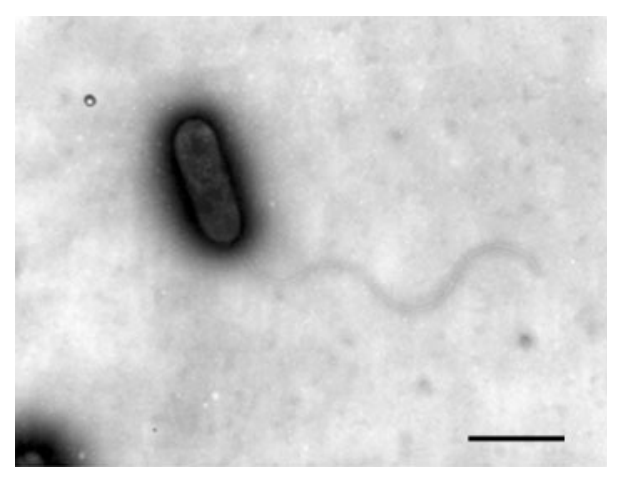

Fig. 1. Electron micrograph of a negatively stained cell of strain $\mathrm{YT}^{\top}$. Bar, $1 \mu \mathrm{m}$.

alkaline phosphatase-streptavidin conjugate (Vector) was used with CDP-Star (Tropix) as substrate.

Cells of strain $\mathrm{YT}^{\mathrm{T}}$ were straight rods, about $1 \cdot 1-1 \cdot 7 \mu \mathrm{m}$ long and $0.5 \mu \mathrm{m}$ wide, and motile by means of a polar flagellum (Fig. 1). Colonies on NB and NB/10 agar were circular, entire, convex, opaque and creamy yellow. Strain $\mathrm{YT}^{\mathrm{T}}$ grew at $27^{\circ} \mathrm{C}$, but not at 4 or $42^{\circ} \mathrm{C}$. The organism was catalase- and oxidase-positive, but negative for nitrate reduction. Strain $\mathrm{YT}^{\mathrm{T}}$ contained $\mathrm{C}_{18: 1}$ as the primary fatty acid component (62\% total fatty acid content) and $\mathrm{C}_{16: 1}$ as the secondary fatty acid component $(13 \%)$. Other fatty acids detected were $\mathrm{C}_{16: 0}(8 \%), 2-\mathrm{OH} \mathrm{C}_{14: 0}(7 \%), \mathrm{C}_{17: 1}$ $(2 \%)$ and $\mathrm{C}_{14: 0}(1 \%)$; the summed amount of unknown acids was $7 \%$. No visible 3 -hydroxy fatty acid spot was detected in TLC of the fatty acid methyl esters. The G+C

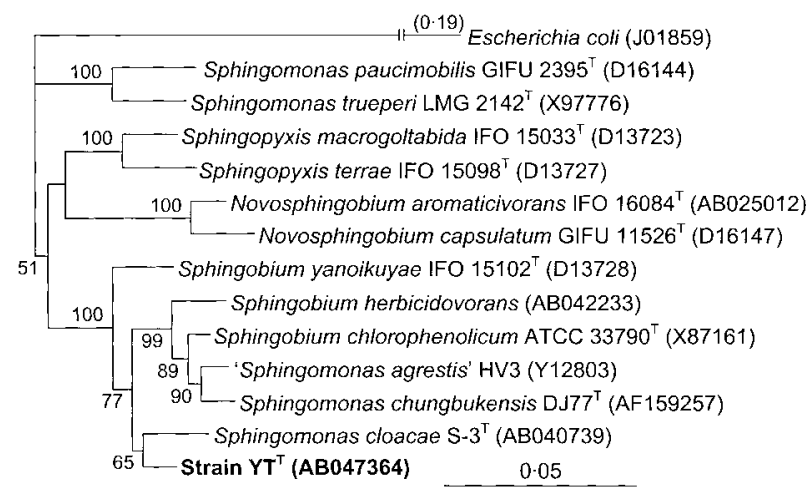

Fig. 2. Unrooted tree showing the phylogenetic relationships of strain $\mathrm{YT}^{\top}$ and representative species of Sphingomonas sensu stricto, Sphingobium, Novosphingobium and Sphingopyxis. Escherichia coli was used as the outgroup. The tree, constructed using the neighbour-joining method, was based on a comparison of a region corresponding to $E$. coli $16 \mathrm{~S}$ rDNA positions 37-1417. Bootstrap values, expressed as percentages of 1000 replications, are given at branching points. Bar, 0.05 nucleotide substitution rate $\left(K_{\text {nuc }}\right)$ units. 
content of strain $\mathrm{YT}^{\mathrm{T}}$ was $66 \cdot 40 \pm 0 \cdot 47 \mathrm{~mol} \%($ mean $\pm \mathrm{SD}$ of five independent determinations).

The phylogenetic tree, based on 16S rDNA sequences, shows that strain $\mathrm{YT}^{\mathrm{T}}$ belongs to the genus Sphingobium (Fig. 2). In addition, the nucleotide signatures specific to the $16 \mathrm{~S}$ rRNA of Sphingobium, i.e. a U:A pair at position 52:359, the presence of $U$ at position 593 and a $U: G$ pair at position $987: 1218$ (Takeuchi et al., 2001), were all found in the sequence of strain $\mathrm{YT}^{\mathrm{T}}$. Takeuchi et al. (2001) have shown that polyamine patterns and nitrate reduction are good diagnostic markers for differentiation of Sphingobium and Sphingomonas sensu stricto. Although polyamines were not analysed in this study, nitrate reduction data suggest that strain $\mathrm{YT}^{\mathrm{T}}$ should be classified in the genus Sphingobium.

A comparison of the biochemical characteristics of strain $\mathrm{YT}^{\mathrm{T}}$ with those of phylogenetically related species of Sphingobium and Sphingomonas and two other Sphingobium species is shown in Table 1 . Of the 11 substrates and five enzyme activities tested, strain $\mathrm{YT}^{\mathrm{T}}$ was positive for only two tests (assimilation of glucose and maltose) and, by this unique catabolic profile, the strain can be clearly differentiated from the other species. Moreover, the whole-cell protein profile of strain $\mathrm{YT}^{\mathrm{T}}$ was compared with those of phylogenetically related Sphingomonas and Sphingobium

Table 1. Biochemical characteristics of strain $\mathrm{YT}^{\top}$, two Sphingomonas species, three Sphingobium species and the type strain of Sphingomonas paucimobilis

Strains: 1, strain $\mathrm{YT}^{\mathrm{T}} ; 2$, Sphingomonas cloacae JCM 10874 ${ }^{\mathrm{T}}$; 3, Sphingobium yanoikuyae JCM $7371^{\mathrm{T}}$; 4, Sphingobium chlorophenolicum DSM 8671; 5, Sphingomonas paucimobilis JCM $7516^{\mathrm{T}} ; 6$, Sphingobium herbicidovorans DSM $11019^{\mathrm{T}}$; 7, Sphingomonas chungbukensis KCTC $2955^{\mathrm{T}}$. Data for strains $1-5$ are from this study and data for strains 6 and 7 are from Kim et al. (2000). None of the strains assimilated D-mannitol, caprate or adipate. Arginine dihydrolase and gelatin hydrolysis activities were not observed in the strains tested. Acid production from glucose was not detected in any strain.

\begin{tabular}{|lcccccccc}
\hline Characteristic & $\mathbf{1}$ & $\mathbf{2}$ & $\mathbf{3}$ & $\mathbf{4}$ & $\mathbf{5}$ & $\mathbf{6}$ & $\mathbf{7}$ \\
\hline Assimilation of: & & & & & & & \\
$\quad$ D-Glucose & + & - & + & + & + & + & + \\
L-Arabinose & - & - & + & - & + & + & + \\
D-Mannose & - & - & - & - & + & - & + \\
N-Acetyl-D-glucosamine & - & - & + & - & + & - & - \\
Maltose & + & - & + & - & + & + & + \\
Gluconate & - & - & + & - & - & + & + \\
Malate & - & - & + & - & + & + & - \\
Citrate & - & - & + & - & - & - & - \\
Activity of: & & & & & & & & \\
$\quad$ Urease & - & - & - & + & - & - & - \\
$\quad \beta$-Galactosidase & - & - & + & - & + & - & - \\
Aesculin hydrolysis & - & - & + & + & + & + & - \\
Nitrate reduction & - & - & - & - & + & - & - \\
& & & & & & & & \\
\hline
\end{tabular}

strains. As shown in Fig. 3, strain $\mathrm{YT}^{\mathrm{T}}$ was distinct from the other strains with respect to the overall proteinbanding pattern. To provide further clear evidence for the low similarity between strain $\mathrm{YT}^{\mathrm{T}}$, Sphingomonas cloacae JCM $10874^{\mathrm{T}}$ and Sphingobium yanoikuyae JCM $7371^{\mathrm{T}}$, DNA-DNA hybridization experiments were performed. The relatedness values between strain $\mathrm{YT}^{\mathrm{T}}$ and all other type strains tested were below $21 \%$. Therefore, it is proposed that strain $\mathrm{YT}^{\mathrm{T}}$ represents a novel species, Sphingobium amiense sp. nov.

\section{Description of Sphingobium amiense sp. nov.}

Sphingobium amiense (a.mi.en'se. N.L. neut. adj. amiense of Ami, Ibaraki, Japan, where the type strain of this organism was isolated).

Gram-negative, aerobic rod. Cells are about $1 \cdot 1-1 \cdot 7 \times$ $0.5 \mu \mathrm{m}$. Colonies on NB agar are circular, entire, convex, opaque and creamy yellow. Able to grow in $\mathrm{NB}$ at $27^{\circ} \mathrm{C}$, but not at 4 or $42^{\circ} \mathrm{C}$. Oxidase- and catalase-positive. Indole, urease and arginine dihydrolase are not produced. Aesculin

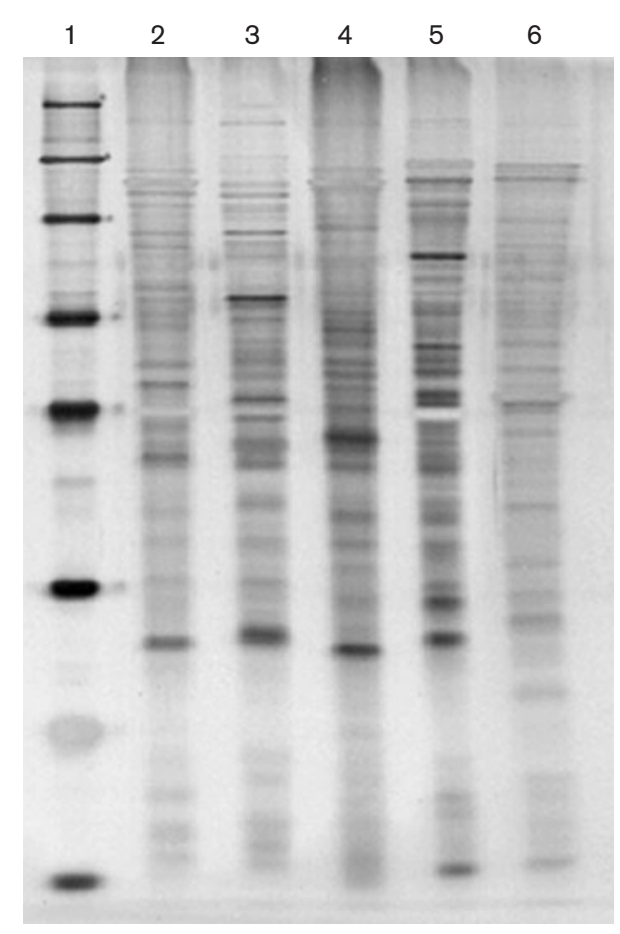

Fig. 3. SDS-PAGE protein profiles of strain $\mathrm{YT}^{\top}$ and phylogenetically related Sphingomonas and Sphingobium species. Lanes: 1, molecular mass markers; 2, strain $\mathrm{YT}^{\mathrm{T}} ; 3$, Sphingomonas cloacae JCM $10874^{\top}$; 4, Sphingobium yanoikuyae JCM $7371^{\top}$; 5, Sphingobium chlorophenolicum DSM $8671 ; 6$, Sphingomonas paucimobilis JCM $7516^{\top}$. The molecular mass markers are (from top to bottom): macroglobulin, $170000 ; \quad \beta$-galactosidase, $116400 ; \quad$ fructose-6-phosphate kinase, 85 200; glutamate dehydrogenase, 55600 ; aldolase, 39 200; triosephosphate isomerase, 26600; trypsin inhibitor, 20100 ; lysozyme, 14300. 
and gelatin are not hydrolysed. Nitrate is not reduced to nitrate. Glucose and maltose are assimilated, but L-arabinose, D-mannose, D-mannitol and $\mathrm{N}$-acetyl-Dglucosamine are not. Nonylphenol, an endocrine disrupter chemical, is degraded in the presence of organic nutrients such as yeast extract, but is not used as a growth substrate. Major non-polar fatty acids are $\mathrm{C}_{18: 1}$ and $\mathrm{C}_{16: 1}$; the major hydroxy fatty acid is $2-\mathrm{OH} \mathrm{C}_{14: 0}$. Sphingoglycolipid is present. The major isoprenoid quinone is ubiquinone Q-10.

The type strain, $\mathrm{YT}^{\mathrm{T}}\left(=\mathrm{IAM} 15006^{\mathrm{T}}=\mathrm{JCM} 11777^{\mathrm{T}}=\mathrm{CIP}\right.$ $107839^{\mathrm{T}}$ ), was isolated from a river sediment sample from Ami-machi, Ibaraki, Japan. The DNA G + C content of this strain is $66 \cdot 4 \mathrm{~mol} \%$.

\section{Acknowledgements}

We are grateful to Professor K. Fukui and Dr T. Inoue for help in electron microscopy and to Dr Y. Kosako for comments and discussions. This work was supported in part by a Grant-in-Aid (no. 13480151) for Scientific Research from the Japan Society of the Promotion of Science.

\section{References}

Ahel, M., Schaffner, C. \& Giger, W. (1996). Behaviour of alkylphenol polyethoxylate surfactants in the aquatic environment. III. Occurrence and elimination of their persistent metabolites during infiltration of river water to groundwater. Water Res 30, 37-46.

Brown, R. J., Conradi, M. \& Depledge, M. H. (1999). Long-term exposure to 4-nonylphenol affects sexual differentiation and growth of the amphipod Corophium volutator (Pallas, 1766). Sci Total Environ 233, 77-88.

de Vries, Y. P., Takahara, Y., Ikunaga, Y. \& 7 other authors (2001). Organic nutrient-dependent degradation of branched nonylphenol by Sphingomonas sp. YT isolated from a river sediment sample. Microb Environ 16, 240-249.

Ezaki, T., Hashimoto, Y. \& Yabuuchi, E. (1989). Fluorometric deoxyribonucleic acid-deoxyribonucleic acid hybridization in microdilution wells as an alternative to membrane filter hybridization in which radioisotopes are used to determine genetic relatedness among bacterial strains. Int J Syst Bacteriol 39, 224-229.

Fujii, K., Urano, N., Ushio, H., Satomi, M., lida, H., Ushio-Sata, N. \& Kimura, S. (2000). Profile of a nonylphenol-degrading microflora and its potential for bioremedial applications. J Biochem 128, 909-916.

Fujii, K., Urano, N., Ushio, H., Satomi, M. \& Kimura, S. (2001). Sphingomonas cloacae sp. nov., a nonylphenol-degrading bacterium isolated from wastewater of a sewage-treatment plant in Tokyo. Int J Syst Evol Microbiol 51, 603-610.

Giger, W., Brunner, P. H. \& Schaffner, C. (1984). 4-Nonylphenol in sewage sludge: accumulation of toxic metabolites from nonionic surfactants. Science 225, 623-625.

Heinis, L. J., Knuth, M. L., Liber, K., Sheedy, B. R., Tunell, R. L. \& Ankley, G. T. (1999). Persistence and distribution of 4-nonylphenol following repeated application to littoral enclosures. Environ Toxicol Chem 18, 363-375.

Ikemoto, S., Kathoh, K. \& Komagata, K. (1978). Cellular fatty acid composition in methanol-utilizing bacteria. J Gen Appl Microbiol 24, $41-49$.
Kim, S.-J., Chun, J., Bae, K. S. \& Kim, Y.-C. (2000). Polyphasic assignment of an aromatic-degrading Pseudomonas sp., strain DJ77, in the genus Sphingomonas as Sphingomonas chungbukensis sp. nov. Int J Syst Evol Microbiol 50, 1641-1647.

Kimura, M. (1980). A simple method for estimating evolutionary rates of base substitutions through comparative studies of nucleotide sequences. J Mol Evol 16, 111-120.

Kinnberg, K., Korsgaard, B., Bjerregaard, P. \& Jespersen, A. (2000). Effects of nonylphenol and 17 beta-estradiol on vitellogenin synthesis and testis morphology in male platyfish Xiphophorus maculatus. $J$ Exp Biol 203, 171-181.

Kloas, W., Lutz, I. \& Einspanier, R. (1999). Amphibians as a model to study endocrine disruptors. II. Estrogenic activity of environmental chemicals in vitro and in vivo. Sci Total Environ 225, 59-68.

Kveštak, R. \& Ahel, M. (1995). Biotransformation of nonylphenol polyethoxylate surfactants by estuarine mixed bacterial cultures. Arch Environ Contam Toxicol 29, 551-556.

Laemmli, U. K. (1970). Cleavage of structural proteins during the assembly of the head of bacteriophage T4. Nature 227, 680-685.

Ohta, H. \& Hattori, T. (1983). Agromonas oligotrophica gen. nov., sp. nov., a nitrogen-fixing oligotrophic bacterium. Antonie van Leeuwenhoek 49, 429-446.

Ohta, H., Hara, H., Fukui, K., Kurihara, H., Murayama, Y. \& Kato, K. (1993). Association of Actinobacillus actinomycetemcomitans leukotoxin with nucleic acids on the bacterial cell surface. Infect Immun 61, 4878-4884.

Pearson, W. R. \& Lipman, D. J. (1988). Improved tools for biological sequence comparison. Proc Natl Acad Sci U S A 85, 2444-2448.

Pinyakong, O., Habe, H. \& Omori, T. (2003). The unique aromatic catabolic genes in sphingomonads degrading polycyclic aromatic hydrocarbons (PAHs). J Gen Appl Microbiol 49, 1-19.

Rudling, L. \& Solyom, P. (1974). The investigation of biodegradability of branched nonylphenol ethoxylates. Water Res 8, 115-119.

Saitou, H. \& Miura, K. (1963). Preparation of transforming deoxyribonucleic acid by phenol treatment. Biochim Biophys Acta 72, 619-629.

Saitou, N. \& Nei, M. (1987). The neighbor-joining method: a new method for reconstructing phylogenetic trees. Mol Biol Evol 4, 406-425.

Skerman, V. B. D. (1967). A Guide to the Identification of the Genera of Bacteria, 2nd edn. Baltimore: Williams \& Wilkins.

Soto, A. M., Justicia, H., Wray, J. W. \& Sonnenschein, C. (1991). p-Nonyl-phenol: an estrogenic xenobiotic released from 'modified' polystyrene. Environ Health Perspect 92, 167-173.

Takeuchi, M., Hamana, K. \& Hiraishi, A. (2001). Proposal of the genus Sphingomonas sensu stricto and three new genera, Sphingobium, Novosphingobium and Sphingopyxis, on the basis of phylogenetic and chemotaxonomic analyses. Int J Syst Evol Microbiol 51, 1405-1417.

Tamaoka, J. \& Komagata, K. (1984). Determination of DNA base composition by reversed-phase high-performance liquid chromatography. FEMS Microbiol Lett 25, 125-128.

Tanghe, T., Dhooge, W. \& Verstraete, W. (1999). Isolation of a bacterial strain able to degrade branched nonylphenol. Appl Environ Microbiol 65, 746-751.

Thompson, J. D., Higgins, D. G. \& Gibson, T. J. (1994). CLUSTAL W: improving the sensitivity of progressive multiple sequence alignment through sequence weighting, position-specific gap penalties and weight matrix choice. Nucleic Acids Res 22, 4673-4680.

White, R., Jobling, S., Hoare, S. A., Sumpter, J. P. \& Parker, M. G. (1994). Environmentally persistent alkylphenolic compounds are estrogenic. Endocrinology 135, 175-182. 